\title{
On the Innovative Design of Urban Squares Based on the Background of Digital Technology
}

\author{
Xia Jin ${ }^{1, \mathrm{a}}, \mathrm{Wu}$ Qiuhui ${ }^{1, \mathrm{~b}}$ \\ ${ }^{1}$ Xiamen University of Technology, Xiamen city, Fujian Province, China
}

\begin{abstract}
Urban square is an important place for modern people's lives, but there exists a common phenomenon of pursuing formal beauty and wide land occupation while ignoring the participation and experience of the users, and lack of innovation. Based on the concept of humanized design, this paper explores the two-way interactive relationship between urban square and the user "people" under the background of digital technology, and fully perceive the mental needs and behavioral pattern of users, by analyzing different groups and types of their activities so as to contribute to a better innovative design of urban squares.
\end{abstract}

\section{Introduction}

In recent years, with the development of social economy, the application of digital technology in the field of urban squares has become more and more widespread, mainly in the areas of human-computer interaction design, multimedia technology, etc., it breaks the traditional environmental design model and provides more diverse, more interesting and unique spatial experience and interaction methods for modern people's urban square activities.

Urban square is an important place for people to gain leisure and gather together. They serve as a significant element in the urban spatial composition ${ }^{[1]}$. Moreover, it is also a cultural symbol of a city to demonstrate its typical urban style and spiritual culture. The quality of people's intellectual life has been gradually improved in modern society, with people's status increasingly enhanced in social life and the "People-oriented philosophy" gaining much attention in China. Hence, an urban square is no longer a place with one single function, which means it should not only meet the functional demand of users, but also accommodate their spiritual needs.

This study focuses on integrating the people-oriented philosophy in the design of urban square. Use digital methods to solve the problems faced by urban square environmental design, and create more diverse and rich urban square spaces. Urban square design should base on people's material and spiritual needs. Through analysis on the user group from mental and behavioral perspectives, hopefully more reasonable and comfortable modern urban squares will be built to meet people's living needs, alleviate urban pressure and provide spiritual and cultural sustenance in a city.

\section{Urban Square and Humanized Design under the Background of Digital Technology}

\subsection{Concept of Urban Square}

Cai Yongjie defined urban square as "a mixture of tangible and intangible elements ... Urban square is both an element in urban design and a social institution with diversified functions (activities); it is an open public space integrated into the urban entities, which meets the demand of people and affects people's behavior ${ }^{[2]}$." From his definition, we can see the term "urban square" has twofold meanings, material space and social activities. Urban square, as an important component of urban spatial structure, is an urban public space for the main purpose of meeting various social activities.

The urban square space design under the background of digital technology is based on the perspective of humanized design, paying attention to people's psychological needs and behavioral activities in the space environment, and further discussing how to use digital technology to improve the current problems, increase users' Participation, experience and interaction, to achieve the innovative design of urban square public space.

\subsection{Research on Humanized Design}

"People are the foundation of humanized design, and the core of design is to meet mental and physical needs of people. Hence, the concept of humanized design is not proposed to pursue novelty. Instead, it was gradually formed in the process of social development. However, the so-called humanized design will lose its significance if the core of design deviates from people. Humanized design is based on such theories as environmental psychology and

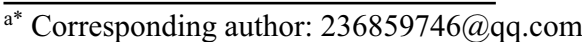

b1632463415@qq.com
} 
behavioral psychology. We should put people first in the spatial design according to people's different needs and psychological characteristics to achieve harmonious coexistence between environment and people [3]." Therefore, the humanized design should be closely linked to the user - "people". Otherwise without sufficient analysis and study on "people" we will drift further apart from the humanized design.

Many Chinese scholars have conducted research in this field, including "Study on Humanized Design of City Square in Hohhot" by Zhang Yiyang, "Case Study on Humanized Philosophy in Modern City SquareTaking Hangzhou as an Example" by Mao Yintao and "Study on the Humanity Design of the Modern City Square" by Zhou et al. The studies pointed out the insufficiencies of city squares, which has deviated from the demand of "people" at the current stage, and discussed the combination between city square design and humanized design. They suggested that people's participation as users should be enhanced and insisted on the idea that people were the main actors of a square so square must serve the people as well as proposed the suggestions and future direction on humanized design.

At present, digital technology is gradually being applied in space design, and humanized design is also attracting attention in people's daily life. The use of modern technology brings new challenges and innovative directions to space design, and makes urban square design more humanized. To meet people's growing needs for a better life.

\subsection{Lack of Innovative Design in Urban Square}

Urban square gradually takes up a larger share in the use of urban space. After people's basic needs were satisfied, their major life pursuit has transformed into spiritual needs. However, the planning and design of a host of urban squares solely pursue visual grandness and wideness, reducing the squares to mere empty and useless displays in the city. In the section of "Existing Problems of Urban Square Design", it can be seen from Figure 1 that fasttraveling electric cars, parents playing with children and an old man lounging in an electric wheelchair all show up in the same picture, which suggests that a variety of people are crowded together and there must be safety concerns (See Figure 2). Functional areas in the square are vaguely divided. Some sites are empty while others are crowded and messy, inconsistent with the surroundings and interfere with main traffic arteries (See Figure1). Meanwhile, there exist serious safety hazards. The square is unable to provide users with shade facilities in hot weather, especially in summer, when the spacious site is empty and hot; with poor lighting at night, crimes may arise within the square, causing potential personal safety hazards (See Figure 3); urban squares are supposed to serve citizen of all walks of life, but the fact is the physical and mental needs of sub-groups and special community are seldom taken into consideration, and lack of reasonable application of modern digital technology; landscape design of urban squares follows the same pattern with a lack of regional and cultural features, making it difficult for urban residents to have a sense of cultural belonging and the like.

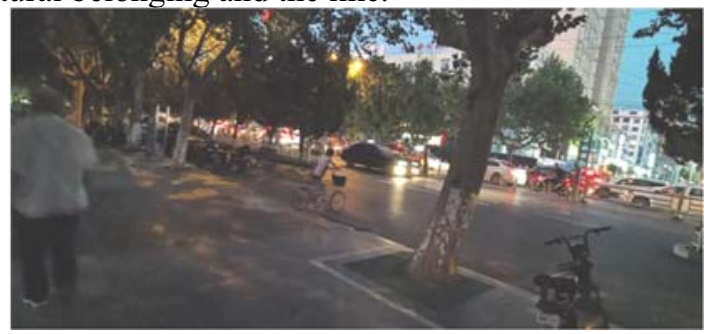

Figure 1 Various modes of transportation intersected with each other (Source: photographed by the author)

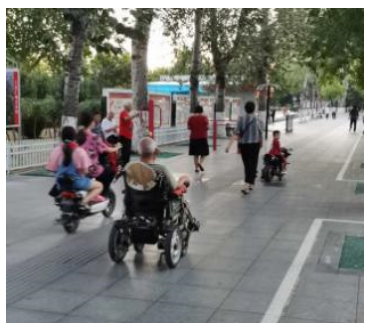

Figure 2 Various modes of transportation intersected with each other (Source:

photographed by the author)

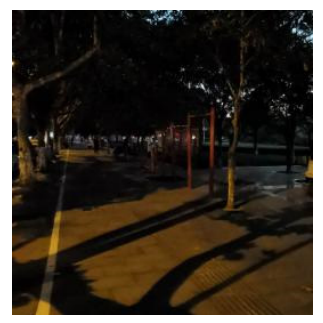

Figure 3 Poor lighting at night (Source: photographed by the author)
Essentially, these problems can be chalked up to a deviation from "people" as the served subject in design. As a result, urban squares are unable to give full play to its value and significance. Therefore, the people-oriented design philosophy should be always kept in mind in every process of square design. Only by fully perceiving and grasping people's mental needs and behavioral rules can we truly understand what is the useful design in line with people's actual needs and use modern digital technology to the design of urban square.

\section{Psychological Demand of Users for Urban Square under the Background of Digital Technology}

Modern city life is undoubtedly fast-paced, hence people have great expectations for their leisure time outside work. In today's increasingly informatized social environment, people's emotions are mostly attached to social networks. In today's social background, people have an even more urgent demand for close communication. And urban square is the most important place for people to interact, communicate and share feelings with each other. Among the users of urban square, there may be a couple of friends walking or chatting on the path of square; or a family is hanging out together at night, with children laughing and playing and parents shaking off the stress from a day's work; or teenagers along with friends performing or showing their talents; or old couples feeling the tranquility of life. From this we can see that urban square is by no means a place for gathering and dispersion but a carrier of life, entertainment and spiritual sustenance of urban residents. 
The development of a city is recorded in the long course of history, constantly filling every corner of the city. As an important factor in the urban space, urban square is a significant carrier to reflect the unique style and humanistic spirit of a city ${ }^{[4]}$. Under the premise of pursuing practical functions, artistic expression cannot be ignored. In the era of information technology, artistic expression is not an excessive pursuit of formal beauty but a concrete expression of a city's humanistic spirit, it is a combination of digital technology and square space art, improve people's participation and interaction. It strengthens people's sense of cultural identity and belonging and creates unique regional and cultural features of a city while displaying the urban culture.

\section{Psychological Needs and Types of Behavioral Activities of Users in the Context of Digital Technology}

\subsection{Different Groups and Their Mental Needs of Users}

Urban square serves a wide coverage of population with complex types. People can be roughly divided by age into children, teenagers, middle-aged and the elderly, etc. Children have a strong dependence on the external environment and more interaction with inherent facilities such as landscape facilities in a small area, but they are also vulnerable to external threats ${ }^{[5]}$. Therefore, children, as a vulnerable group, cannot perform activities alone in the square, and must be accompanied by their families (See Figure 4). In addition, attention should be paid to arranging interactive space in the square to facilitate exchanges among children (See Figure 5).

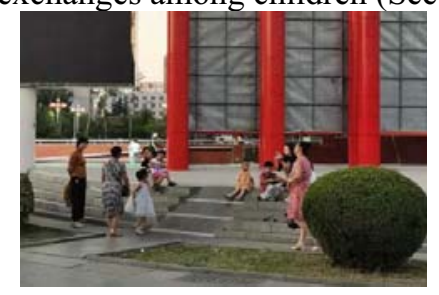

Figure 4 Children should be accompanied by parents (Source: photographed by the author)

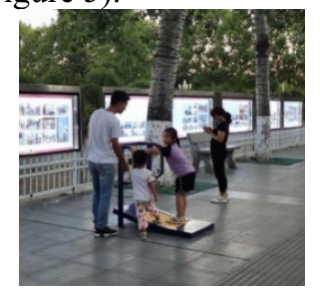

Figure 5 A lack of children recreation facilities (Source: photographed by the author)
Teenagers are energetic and active and often have the need to demonstrate their talents, such as skateboard, roller-skating, hip-pop, music or theatrical performance, etc. (See Figure 6). But this type of activity has certain requirements for the venue. Meanwhile, during the design of the square, such activities may be in conflict with the daily performance of "square dance". Therefore, special attention should be paid to the square planning to balance the demand of different groups.

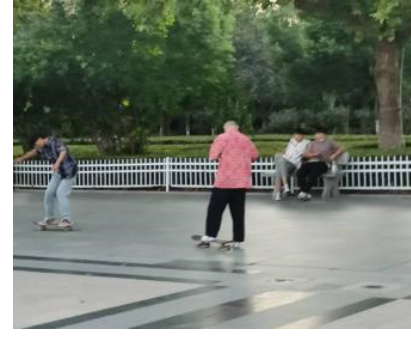

Figure 6.Teenager talent show (Source: photographed by the author)

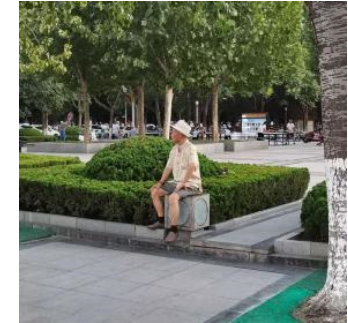

Figure 7Old man sitting alone (Source: photographed by the author)
Middle-aged people are more likely to show up with their family or take children outside for fun or accompany the elderly with inconvenience. The elderly people prefer quiet and pleasant sites because of their physical inability (See Figure 7). From the perspective of helping and caring for the elderly, special consideration should be paid to them due to the loss of self-care ability to varying degrees [6]; among them is the disabled in a special community, of which safety and convenience in their spatial use should be guaranteed by publicizing and improving unimpeded design. To sum up, activity types of different groups must be taken into account in the process of urban square planning and design, while increasing digital technology service facilities of different functions and identifying function positioning of spatial planning to avoid one single function and enrich the spatial level of urban square.

\subsection{Types of Behavioral Activities and Mental Needs of Users}

Types of users' activities in urban squares basically include walking, chatting, dating, playing cards and chess, gatherings, exercising and performing, etc., among which different types of activities have different behavior and mental needs for the design of urban square.

First of all, one of the most common types of urban square activities is walking. The main activity group usually has no clear destination, which is the user scattered for leisure with mobile routes. Hence, the route circulation planning should be considered in road planning to avoid "the end of road", making people feel the guidance of road without thinking too much so that they can keep walking. For the crowd for a short pass, suitable and direct roads should be provided with winding paths reduced, while attention should be paid to safety issues caused by the intersection of different pedestrian routes and transportation means. It is worth noting that there will be at least one purpose in activities whether it is purposeful fast-moving or a leisure walk without a clear purpose. And people have a natural instinct for high output with low input. When they are determined to move toward a place, they will subconsciously display a behavioral tendency as indicated in the theory of minimum energy dissipation, namely the shortest time is consumed to reach the destination with the least amount of efforts. This is why we see in our daily life the grass or the green belt trampled for multiple times to form a road. Therefore, we cannot violate the behavioral rules of human activities in excessive pursuit of artistically formal beauty in the road 
planning, of which the loss outweighs the gain.

Moreover, the common types of urban square activities with fewer participants comprise chatting, reposing and dating, etc., which have different demands for privacy. There are six types of privacy such as solitude, isolation, retention, anonymity, intimate contact with friends and family members ${ }^{[7]}$. Privacy in the planning and design of urban square has been applied to the formation of space and grasp of facilities scale. The impact of facility size on people can hardly be perceived in a large-scale space. However, if the space is gradually narrowed, the users will get closer and immediately enlarge or narrow the distance from others based on their behavioral activities as one person's personal bubble overlap with that of others ${ }^{[8]}$. Users should be provided with a comfortable distance required by different types of activities in the scale design of rest seats. Meanwhile, this type of behavioral activities is more inclined to quiet and relatively independent space in terms of the demand for spatial use. Hence, we should put emphasis on creating a semi-private space without affecting others and also preventing interruptions from others.

Finally, the common urban square activities with a large number of participants include group fitness (square dance, Tai Chi, ballroom dance, etc.), artistic or sports activities, and intensive gathering activities of small groups (playing cards, playing mahjong, chess), etc. These activities pose certain demands for the venue, and thus will cause conflicts in competition for the venue. Meanwhile, these activities, with the nature of "performance", are attractive to others when performing. Seeing and being seen has always been the most vivid game in the square ${ }^{[9]}$. Everyone wants to observe others while not being perceived by others. In addition, it also shows that people are more inclined to stay on the edge of the urban square, which can not only give themselves a sense of security and stability, but also facilitate their observation on the activities in the center of the square. Only when they crowd the edge of the square will people move to the central zone ${ }^{[10]}$. Therefore, the planning and design of facilities such as the seats for rest should fully consider the behavior and mental needs of users. Large-scale performance activities, such as urban publicity, artificial performances, commercial activities, etc., will inevitably be held in the urban square. Compared with other activities, large-scale performances are larger in scale and have more participants. Therefore, the square should be provided with corresponding crowd carrying areas.

The diversity of user activities determines the diversity of urban square functions. For the urban square, users are like many small dots in a plane, and the dots are connected to form a line and then converge into a surface. If the architectural and landscape entities in the urban square are hidden, the distribution of users in the square can most intuitively reflect their distribution characteristics and needs. The development of digital technology has many influences on the space design of urban squares, and there are new requirements in terms of design content, methods, expression forms and design goals. Therefore, only indepth investigation and analysis on the behavioral characteristics and needs of the users can we make reasonable use of digital technology to make the planning and design of the urban square space fit the actual needs of the users better, thus building a more comfortable and pleasant urban square.

\section{Innovative Embodiment of Humanized Design of Urban Square under the Background of Digital Technology}

\subsection{Artistic Embodiment of Digital Technology in Urban Square Design}

The traditional art design of public space in urban squares pays more attention to the appreciation of art objects, and there is a certain distance between people and objects. This form of viewing is relatively simple and still in the primary aesthetic stage ${ }^{[11]}$. In the era of digital technology information, the traditional form of "appreciating" artworks should be broken, and digital technology should be used to provide a new way for the artistic expression of urban square design. Under the influence of digital technology, the artistic expression of urban square design pays more attention to interaction, functionality and multiple value characteristics. This will bring people a richer experience of the place and have a more positive impact on society.

\subsection{The Interactive Embodiment of Digital Technology in Urban Square Design}

The development of society and the advancement of technology have made people not only satisfied with the visual impact, but with the support of digital media technology, it has brought more possibilities for urban square space design. Multi-sensory elements such as vision, hearing, smell and touch are applied to the public art and public infrastructure in the city square, bringing users a deeper sensory stimulation and richer interactive experience.

Digital technology has played a guiding role in the field of interactive design. It has established a new type of experience activity mode. "Interaction" closely links the relationship between people, objects and space. The thinking of city square design has also changed the thinking and behavior of users. Through interactive experience, it further changes people's emotional cognition and spiritual world.

\subsection{The functional embodiment of digital technology in urban square design}

The functionality of digital technology in city square design mainly reflects its commercial value, public information dissemination, barrier-free facilities, and promotion of communication. First of all, digital technology is widely used in the commercial field. In urban squares, whether it is in the promotion of commercial advertisements or in the creation of place atmosphere, the combination of space design and digital technology can bring certain economic benefits to enterprises or places. Secondly, in addition to commercial 
value, digital technology is also an important channel for public information dissemination. It serves as an important channel for public health propaganda, cultural propaganda, policy interpretation, information announcements, etc. in public spaces, enabling people to obtain public information directly and effectively information. In addition, digital technology can also help people's daily life well, especially for people with visual and hearing impairments or physical disabilities. Through a more humane design of barrier-free facilities, it can well assist people with disabilities to use and solve problems in life. In addition, due to the interactive nature of digital technology, more opportunities for communication between people and objects and between people have been increased in the urban square space, which promotes communication between people.

\section{Conclusion}

From the point of humanized design, the mental needs and behavior types of "people" as users in the urban square were analyzed. Based on the background of digital technology, many requirements for urban square innovation design were put forward with the aim to guide the improvement of the design. The use of modern digital technology, only by fully grasping the mental needs and behavior rules of people as users in urban squares, can the "people-oriented" concept be incorporated into the design of urban squares, thereby changing the status of urban squares with single function and supremacy in form. In this paper, we summarized the mental needs and activity types of the users, it also summarizes the artistic, interactive, and functional aspects of digital technology in urban squares. with an aiming to guide future research and provide a reference for humanized design, thereby passing on the innovation design concept.

\section{Foundation Project}

Xiamen Municipal Study Abroad Research Project (50319003)

Social Science Research Project of Xiamen University of Technology (40419001)

\section{References}

1. Zhai, Y.K. (2019) Embodiment of Humanized Landscape Design of Modern Urban Square. J. Design, 32 (19): 150-151.

2. Cai,Y.J. (2006)Urban Square.Southeast University Press,Nanjing.

3. Xie,H. (2019)Research on Optimization Design of Humanized Upgrading and Reconstruction of Feicui Lake Park in Hefei [D]. Anhui: Anhui Agricultural University.

4. Lei,X.H. (2019)The Regional Expression in the Design of Urban Leisure Square-Taking the Quality Improvement and Reconstruction Design of Hengyang Sun Square as An Example. J. Residential
Property Industry, (06):17-21.

5. Li,A.,Dong,S.j. (2016)Investigation and Research on Children's Behavior Activities in Urban SquareTaking Zhangjiakou City as An Example. J. Journal of Hebei University of Architecture, 34 (03): 82-86 +91 .

6. Zuo,S.Q. (2015)Research on the Design of Square Open Space Based on the Needs of the Elderly [D]. Beijing: China Academy of Forestry Sciences.

7. Hu,Z.F.,Lin,Y.1. (2018)Environmental Psychology:environment behavior research and its design application.China Construction Industry Press, Beijing.

8. Zhang, W. (2012)Application of Environmental Psychology in Urban Square Design. J. Anhui Agricultural Science, (11): 6681-6682 + 6709.

9. Cheng,Y.H. (2019)Thinking on Urban Square Design Approach Based on Environmental Behavior. J. Fujian Quality Management, (3):268-269.

10. Fu,Y.H.,Chen,F.Z.,Shan,X.Q. (2018)Research on spatial user behavior and environmental response of urban park plaza. J. China Real Estate Industry,(4):59-60.

11. Tang,L.Y. (2017)Discussion on the innovative design mode of landscape art under the background of digital information technology.J. Packaging Engineering, 38 (8): 53-57. 